VALVE DISEASE

\section{Should patients with asymptomatic mild or moderate aortic stenosis undergoing coronary artery bypass surgery also have valve replacement for their aortic stenosis?}

Shahbudin H Rahimtoola

Division of Cardiology, Department of Medicine, University of Southern California and LAC+USC Medical Center, Los Angeles, California, USA

The older you get, the closer you are to death -an old Asian saying

$\mathrm{I}$ n 1994-96, three studies described patients who had previously undergone coronary artery bypass graft surgery (CABG) and then had subsequent aortic valve replacement (AVR) (the aortic stenosis was "mild to moderate" at time of initial CABG); these patients were subsequently associated with a "high" operative mortality of $14-19 \% .^{1-3}$

From these studies arose the rationale that patients who have mild to moderate aortic stenosis at the time of CABG will develop severe aortic stenosis within 10 years; such patients should therefore have combined CABG+AVR at time of initial bypass surgery. ${ }^{1-3}$

There were several problems with this rationale, which have been previously described in detail and are summarised below. ${ }^{4}$

- Two subsequent studies showed that the operative mortality for later AVR, if necessary, was not significantly different from those undergoing CABG+AVR $(0 \%$ and $7.7 \%) .^{56}$

- Most importantly, these studies provided no information on the numbers of patients during the same time period who had mild to moderate aortic stenosis but did not require AVR during subsequent follow up. ${ }^{4}$

- There was little or no documentation to show that the aortic stenosis was mild to moderate at the time of the initial CABG. Moreover, some patients already had severe aortic stenosis at the time of initial CABG which was misdiagnosed. ${ }^{4}$

- At time of subsequent AVR, the documentation showing that aortic stenosis was severe was sketchy. Many patients had angina as their symptom and $46-75 \%$ of these patients also needed repeat CABG at the time of late AVR. ${ }^{4}$

Correspondence to: Shahbudin $\mathbf{H}$ Rahimtoola MD, Distinguished Professor, University of Southern California, 2025 Zonal Avenue, Los Angeles, CA 90033, USA of the patients' clinical condition at time of initial CABG and at the time of late AVR. At the time of late AVR some of the studies stated that many patients were in heart failure and New York Heart Association (NYHA) functional classes III and IV.
- The rate of progression of aortic stenosis, the manner of progression and whether it was linear or not, and factors determining more rapid progression were not fully known, especially in patients who had undergone CABG. ${ }^{4}$

\section{Severity of aortic stenosis}

Aortic stenosis is considered to be mild when the calculated aortic valve area (AVA) is $>1.5 \mathrm{~cm}^{2}$ (table 1$) .^{8-12}$ An AVA $\leqslant 1.0 \mathrm{~cm}^{2}$ or an AVA index $\leqslant 0.6 \mathrm{~cm}^{2} / \mathrm{m}^{2}$ signify severe aortic stenosis. Reliance on gradients alone poses problems which have been previously described in detail. ${ }^{4}$

The gradient across an aortic valve is related to flow across the valve in systole and is a "per beat", and not a "per minute", function. ${ }^{4} 1012$ Thus, aortic valve gradient (AVG) is dependent on forward stroke volume from the left ventricle and systolic ejection time, both of which are a function of heart rate, and of left ventricular preload, afterload and myocardial contractility. ${ }^{41012}$ AVG is also dependent on the distal obstruction (systemic vascular resistance), and thus, on the pressure in the ascending aorta. ${ }^{12}$ Therefore, AVGs can change from one minute to the next.

Measurement of gradients by Doppler ultrasound is clinically useful. However, their limitations must be kept in mind. Feigenbaum stated: "None of the echocardiographic techniques measures intravascular pressures directly." ${ }^{13}$ The modified Bernoulli equation used to estimate gradients from Doppler velocities makes many assumptions, ignores several factors, and has been shown to be inaccurate in several subgroups. ${ }^{4}$

Peak AVG by Doppler poses particular problems ${ }^{4}$ and it is better to calculate mean AVG. In 636 patients studied by cardiac catheterisation over a 10 year period, no AVG (peak or mean) was found that was both sensitive and specific for severe aortic stenosis. ${ }^{14} \mathrm{~A}$ mean gradient of $\geqslant 50 \mathrm{~mm} \mathrm{Hg}$ or a peak gradient of $\geqslant 60 \mathrm{~mm} \mathrm{Hg}$ were "specific" with a $90 \%$ or more positive predictive value. However, it was not possible to find a lower limit with $90 \%$ negative predictive value. The authors emphasised the importance of measuring $\mathrm{AVA}^{14}$ in all patients with suspicion of severe aortic stenosis with a cardiac catheterisation mean AVG $<50 \mathrm{~mm} \mathrm{Hg}$ (present in $50 \%$ of patients in their study) and a peak of $<60 \mathrm{~mm} \mathrm{Hg}$ (present in $47 \%$ of patients in their study).

Patients with low mean AVG and reduced left ventricular ejection fraction $(<0.35)$ may have severe aortic stenosis and frequently have

Table 1 Criteria for severity of aortic stenosis

\begin{tabular}{lllll}
\hline Aortic stenosis & $\begin{array}{l}A V A^{8} \\
\left(\mathrm{~cm}^{2}\right)\end{array}$ & $\begin{array}{l}A V A^{9} \\
\left(\mathrm{~cm}^{2}\right)\end{array}$ & $\begin{array}{l}A V A^{10} \\
\left(\mathrm{~cm}^{2}\right)\end{array}$ & $\begin{array}{l}A V A \text { index } \\
\left(\mathrm{cm}^{2} / \mathrm{m}^{2}\right)\end{array}$ \\
\hline Mild & $>1.5$ & $>1.5$ & $>1.5$ & $>0.9$ \\
Moderate & $0.95-1.4$ & $0.8-1.5$ & $>1.0-1.5$ & $>0.6-0.9$ \\
Severe & $<0.9$ & $<0.8$ & $\leqslant 1.0$ & $\leqslant 0.6$
\end{tabular}

Superscripts denote reference source.

AVA, aortic valve area. 


\section{Results of CABG alone}

- An operative (30 day) mortality of $\leqslant 3 \%$ in those aged $<80$ years and of $\geqslant 8.1 \%$ in those aged $\geqslant 80$ years (table 2$)^{16-19}$

- Many patients who undergo this operation will die from coronary artery disease, graft disease, graft occlusion, left ventricular dysfunction, and other comorbid conditions; approximately $30 \%$ at 10 years (table 3) ${ }^{16171920}$

- A certain percentage will need repeat revascularisation for graft disease, graft occlusion, and progression of coronary artery disease-approximately $16 \%$ at 10 years. ${ }^{16}$

\section{Results of CABG+AVR initially}

An average operative mortality of $7.9 \%$ in those aged $<80$ years and of $10.6 \%$ in those $\geqslant 80$ years (table 2 )

Many patients will die from coronary artery disease, graft disease, graft occlusion, left ventricular dysfunction, and other comorbid conditions, and the survivors will be subject to prosthesis related deaths-approximately $60 \%$ at 10 years (table 3 )

A certain percentage will need repeat revascularisation for graft disease, graft occlusion, and progression of coronary artery disease-approximately $16 \%$ at 10 years. ${ }^{16}$

A significant percentage will have prosthesis related complications, including reoperation for prosthetic valve malfunction-up to approximately $2-6 \%$ per year. ${ }^{21} 22$

associated coronary artery disease; these patients therefore pose a more difficult clinical problem. ${ }^{12}$ However, they benefit from $\mathrm{CABG}+\mathrm{AVR}$, and thus there is a need for early diagnosis and surgery in such patients. ${ }^{12} 15$

\section{Resolution of the problem}

This clinical situation is more common in older patients (average age at time of initial CABG $\geqslant 60$ years $)^{4}$ and their mortality with or without surgery can be expected to be greater than in younger patients, especially if they have associated comorbid conditions. In the cited studies, late AVR was performed on average 8-9 years after the initial CABG. ${ }^{4}$

Since there are no good prospective studies or trials addressing this clinical circumstance, one way to proceed is to: (1) determine the 10 year results of $\mathrm{CABG}+\mathrm{AVR}$; and (2) determine the 10 year results of isolated CABG and add to this the outcome of patients with mild to moderate aortic stenosis.
Table 2 Operative mortality

\begin{tabular}{|c|c|c|c|c|}
\hline & Years & Age & $\begin{array}{l}\text { Number of } \\
\text { patients }\end{array}$ & $\begin{array}{l}\text { Operative mortality } \\
(\%)\end{array}$ \\
\hline \multicolumn{5}{|l|}{$C A B G$} \\
\hline Rahimtoola et $a l^{16}$ & $1974-88$ & & 7026 & 2.1 \\
\hline Davis $e t a l^{17}$ & 1974-79 & & 8213 & 2.9 \\
\hline Alexander $e t a l^{18}$ & 1994-97 & $\begin{array}{l}<80 \text { years } \\
\geqslant 80 \text { years }\end{array}$ & $\begin{array}{r}60161 \\
4306\end{array}$ & $\begin{array}{l}3.0 \\
8.1\end{array}$ \\
\hline \multicolumn{5}{|l|}{$C A B G+A V R$} \\
\hline Alexander et $a l^{18}$ & 1994-97 & $<80$ years & 1690 & 7.9 \\
\hline & & $\geqslant 80$ years & 345 & 10.6 \\
\hline Cohn $e t a l^{19}$ & $1972-97$ & & 365 & 6.0 \\
\hline
\end{tabular}

AVR, aortic valve replacement; CABG, coronary artery bypass surgery.

\section{Mild aortic stenosis}

Of two studies on the natural history of mild aortic stenosis (AVA $>1.5 \mathrm{~cm}^{2}$ ) documented by cardiac catheterisation, one showed that by 10 years $8 \%$ of patients had developed severe aortic stenosis, ${ }^{9}$ and in the other the event rate (which includes AVR plus mortality before and after AVR) was $15 \% .^{8}$ Thus, it is likely that, at most, $\leqslant 12 \%$ of survivors who initially did not have AVR will develop severe aortic stenosis; even if one assumes that the operative mortality of late AVR in these patients may be up to $15 \%$ (probably too high an estimate of mortality rate with modern surgical technique), the total

Table 3 Ten year mortality

\begin{tabular}{|c|c|c|c|c|}
\hline & Years & $\begin{array}{l}\text { Mean age } \\
\text { (years) }\end{array}$ & $\begin{array}{l}\text { Number of } \\
\text { patients }\end{array}$ & $\begin{array}{l}10 \text { year mortality } \\
(\%)\end{array}$ \\
\hline \multicolumn{5}{|l|}{$C A B G$} \\
\hline Rahimtoola et $a l^{16}$ & $1974-88$ & 61 & 7026 & 26 \\
\hline Davis $e t a l^{17}$ & $1974-79$ & 56 & $\begin{array}{l}8213 \\
(15239)\end{array}$ & $\begin{array}{l}33 \\
(30)\end{array}$ \\
\hline \multicolumn{5}{|l|}{$C A B G+A V R$} \\
\hline Cohn et $a l^{19}$ & $1974-97$ & 69 & 365 & $55^{\star}$ \\
\hline Peterseim et $a l^{20}$ & $1976-96$ & 63 & $\begin{array}{l}347 \\
(712)\end{array}$ & $\begin{array}{l}65 \\
(60)\end{array}$ \\
\hline
\end{tabular}

^Excludes operative mortality of $6 \%$

Table 4 Expected outcome of patients with severe coronary artery disease and mild aortic stenosis

\begin{tabular}{|c|c|c|c|c|}
\hline & \multirow[b]{2}{*}{$\begin{array}{l}\text { Initial } \\
C A B G+ \\
A V R\end{array}$} & \multirow[b]{2}{*}{$\begin{array}{l}\text { Initial } C A B G \\
+ \text { later } A V R \text { if } \\
\text { necessary }\end{array}$} & \multicolumn{2}{|c|}{$\begin{array}{l}\text { Initial } C A B G+A V R \text { is } \\
\text { associated with: }\end{array}$} \\
\hline & & & $\begin{array}{l}\text { Unnecessary } \\
\text { AVR }\end{array}$ & $\begin{array}{l}\text { Excess } \\
\text { mortality }\end{array}$ \\
\hline $\begin{array}{l}\text { Total number of patients } \\
1 \text {. At } 30 \text { days }\end{array}$ & 100 & 100 & & \\
\hline (a) Mortality & 8 & 3 & 100 & 5 \\
\hline $\begin{array}{l}\text { 2. At } 3 \text { years } \\
\text { (a) Mortality } \\
\text { (b) Late AVR in survivors }\end{array}$ & $\begin{array}{c}18 \dagger \\
0\end{array}$ & $\begin{array}{l}9^{\star} \\
0\end{array}$ & 100 & 9 \\
\hline $\begin{array}{l}\text { 3. At } 5 \text { years } \\
\text { (a) Mortality } \\
\text { (b) Late AVR/reop AVR in survivors } \\
\text { (c) } 15 \% 30 \text { day mortality of late AVR } \\
\text { (d) Total deaths }\end{array}$ & $\begin{array}{c}30 \dagger \\
0 \\
0 \\
30\end{array}$ & $\begin{array}{c}15^{\star} \\
5 \\
1 \\
16\end{array}$ & 95 & 14 \\
\hline $\begin{array}{l}\text { 4. At } 10 \text { years } \\
\text { (a) Mortality } \\
\text { (b) Late AVR/reop AVR in survivors } \\
\text { (c) } 15 \% 30 \text { day mortality of late AVR } \\
\text { (d) Total deaths }\end{array}$ & $\begin{array}{c}60 \dagger \\
6 \\
1 \\
61\end{array}$ & $\begin{array}{l}30^{\star} \\
9 \ddagger \\
2 \\
32\end{array}$ & 91 & 29 \\
\hline
\end{tabular}

\section{${ }^{\star}$ Mortality after $\mathrm{CABG}$}

†Mortality after CABG+AVR

$¥$ No late deaths from mild aortic stenosis other than mortality after late AVR for late severe aortic stenosis.

Repeat revascularisation should be similar in both groups; its incidence and associated mortality are not included.

Ten year complications after revascularisation and with prosthetic heart valves are not included. Mortality at time of reoperation are included in the 5 and 10 year data. The assumed $15 \%$ mortality for reoperation is probably too high. 


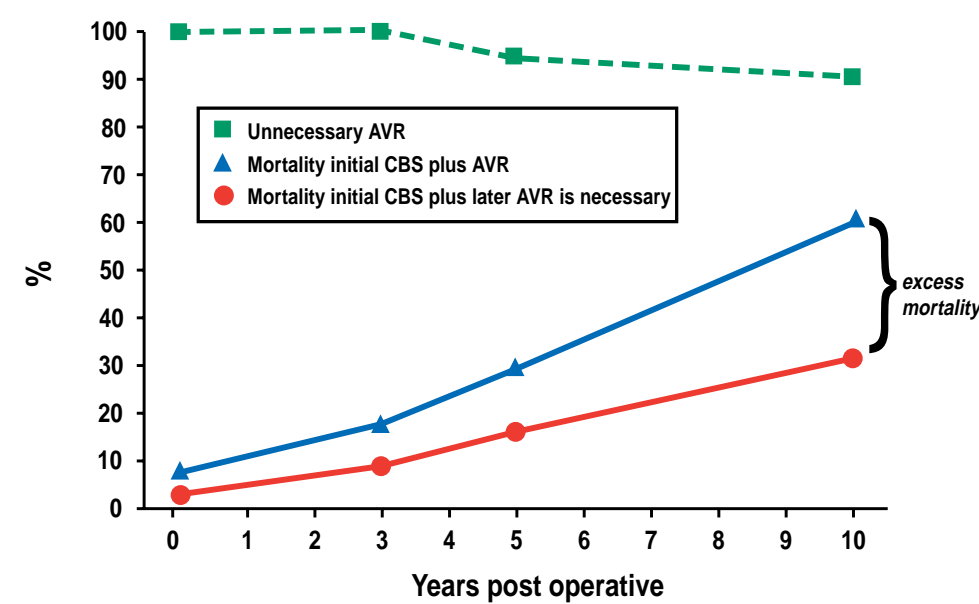

Figure 1. Projected patient outcomes in those with severe coronary artery disease who are to undergo coronary bypass surgery and also have mild aortic stenosis. AVR, aortic valve replacement; CBS, coronary bypass surgery.

number of deaths from late AVR will be very small. Moreover, at the end of five years only $5 \%$ will need AVR.

If initially 100 patients had CABG+AVR, then at the end of 30 days, three years, and five years, the expected number of unnecessary AVRs would be 100, 100, and 95 and the number of excess deaths would be five, nine, and 14 , respectively (table 4 ).

At 10 years, to reduce one death from late AVR by a policy of AVR for mild aortic stenosis at time of initial CABG in 100 patients (table 4), the projected cumulative incidence of unnecessary AVR would be 91 and that of excess deaths would be 29 , when compared to a policy of initial isolated CABG and later AVR if necessary (fig 1). It should be noted that figures for reoperation, and mortality associated with reoperation, are included in the 10 year estimated outcome data in table 4 and fig 1 .

Table 5 Expected outcome of patients with severe coronary artery disease and moderate aortic stenosis

\begin{tabular}{|c|c|c|c|c|}
\hline & \multirow{2}{*}{$\begin{array}{l}\text { Initial } \\
C A B G+ \\
A V R\end{array}$} & \multirow{2}{*}{$\begin{array}{l}\text { Initial } \\
C A B G+ \\
\text { later } A V R \text { if } \\
\text { necessary }\end{array}$} & \multicolumn{2}{|c|}{$\begin{array}{l}\text { Initial } C A B G+A V R \text { is } \\
\text { associated with: }\end{array}$} \\
\hline & & & $\begin{array}{l}\text { Unnecessary } \\
\text { AVR }\end{array}$ & $\begin{array}{l}\text { Excess } \\
\text { mortality }\end{array}$ \\
\hline Total number of patients & 100 & 100 & & \\
\hline $\begin{array}{l}\text { 1. At } 30 \text { days } \\
\text { (a) Mortality }\end{array}$ & 8 & 3 & 100 & 5 \\
\hline $\begin{array}{l}\text { 2. At } 3 \text { years } \\
\text { (a) Mortality } \\
\text { (b) Late AVR in survivors }\end{array}$ & $\begin{array}{c}18+ \\
0\end{array}$ & $\begin{array}{l}9^{\star} \\
0\end{array}$ & 100 & 9 \\
\hline $\begin{array}{l}\text { 3. At } 5 \text { years } \\
\text { (a) Mortality } \\
\text { (b) Late AVR/reop AVR in survivors } \\
\text { (c) } 15 \% 30 \text { day mortality of late AVR } \\
\text { (d) Total deaths }\end{array}$ & $\begin{array}{c}30 \dagger \\
0 \\
0 \\
30\end{array}$ & $\begin{array}{r}15^{\star} \\
15 \\
2 \\
17\end{array}$ & 85 & 13 \\
\hline $\begin{array}{l}\text { 4. At } 10 \text { years } \\
\text { (a) Mortality } \\
\text { (b) Late AVR/reop AVR in survivors } \\
\text { (c) } 15 \% 30 \text { day mortality of late AVR } \\
\text { (d) Total deaths }\end{array}$ & $\begin{array}{c}60 \dagger \\
6 \\
1 \\
61\end{array}$ & $\begin{array}{c}30^{\star} \\
46 \ddagger \\
7 \\
37\end{array}$ & 54 & 24 \\
\hline
\end{tabular}

${ }^{\star}$ Mortality after $\mathrm{CABG}$

tMortality after CABG+AVR

$\ddagger$ Events (death+AVR) at 10 years is $65 \%$; for this analysis it was considered $65 \%$ of 70 survivors

(that is, 46) would need late AVR which is most likely an overestimate.

Repeat revascularisation similar in both groups; its incidence and associated mortality are not included.

Ten year complications after revascularisation and with prosthetic heart valves are not included. Mortality at time of reoperation are included in the 5 and 10 year data. The assumed $15 \%$ mortality for reoperation is probably too high.

\section{Summary}

- The results after 10 years of a policy of initial CABG+AVR for mild and for moderate aortic stenosis are summarised in table 6

A uniform policy of initial CABG for severe CAD plus AVR cannot be supported at this time for:

- mild aortic stenosis (AVA $>1.5 \mathrm{~cm}^{2}$,

AVA index $\left.>0.9 \mathrm{~cm}^{2} / \mathrm{m}^{2}\right)$

- moderate aortic stenosis (AVA

$>1.0-1.5 \mathrm{~cm}^{2}$, AVA index

$>0.6-0.9 \mathrm{~cm}^{2} / \mathrm{m}^{2}$ )

In view of the uncertainty of rate of progression of calcific aortic stenosis in older patients, at this time, CABG for severe coronary artery disease plus AVR may be reasonable for moderate aortic stenosis (AVA $\leqslant 1.2 \mathrm{~cm}^{2}$, AVA index $\left.\leqslant 0.8 \mathrm{~cm}^{2} / \mathrm{m}^{2}\right)$ in patients $\geqslant 60-65$ years of age, provided the patients are not at high risk for thromboembolism, and thus can receive a biological valve (bioprosthesis)

In patients with severe coronary artery disease and low mean AVG great care should be taken to ensure that severe aortic stenosis is not being misdiagnosed, especially in those in whom the left ventricular ejection fraction is reduced

All patients with severe aortic stenosis (AVA $\leqslant 1.0 \mathrm{~cm}^{2}$, AVA index $\leqslant 0.6 \mathrm{~cm}^{2} / \mathrm{m}^{2}$ ) and severe coronary artery disease should have AVR at the time of CABG.

Properly designed and carefully performed prospective studies are needed.

\section{Moderate aortic stenosis}

The natural history of moderate aortic stenosis is more difficult to estimate for a number of reasons. One study ${ }^{8}$ provided information only on event-free survival which was $100 \%$ at the end of three years and $35 \%$ at the end of 10 years. Since all the events occurred in the intervening years, the event-free survival at five years can be expected to be about $81 \%$. The event-free survival includes AVR plus mortality before and after AVR; the need for late AVR is not given separately. ${ }^{8}$

A further study classified moderate aortic stenosis as an AVA of $0.8-1.5 \mathrm{~cm}^{2} .{ }^{9}$ However, another study has shown that the incidence of death and AVR in patients with "moderate" aortic stenosis (AVA of $0.7-1.2 \mathrm{~cm}^{2}$ ) is $10 \%$ per year ${ }^{23}$; many of these patients in fact had severe aortic stenosis, ${ }^{23}$ - that is, AVA $\leqslant 1.0 \mathrm{~cm}^{2}$ (table 1).

Other issues include the problem of assessing aortic stenosis progression, which has been extensively reviewed, ${ }^{4}$ and the conflicting data over whether aortic stenosis in older patients progresses more rapidly than in younger 

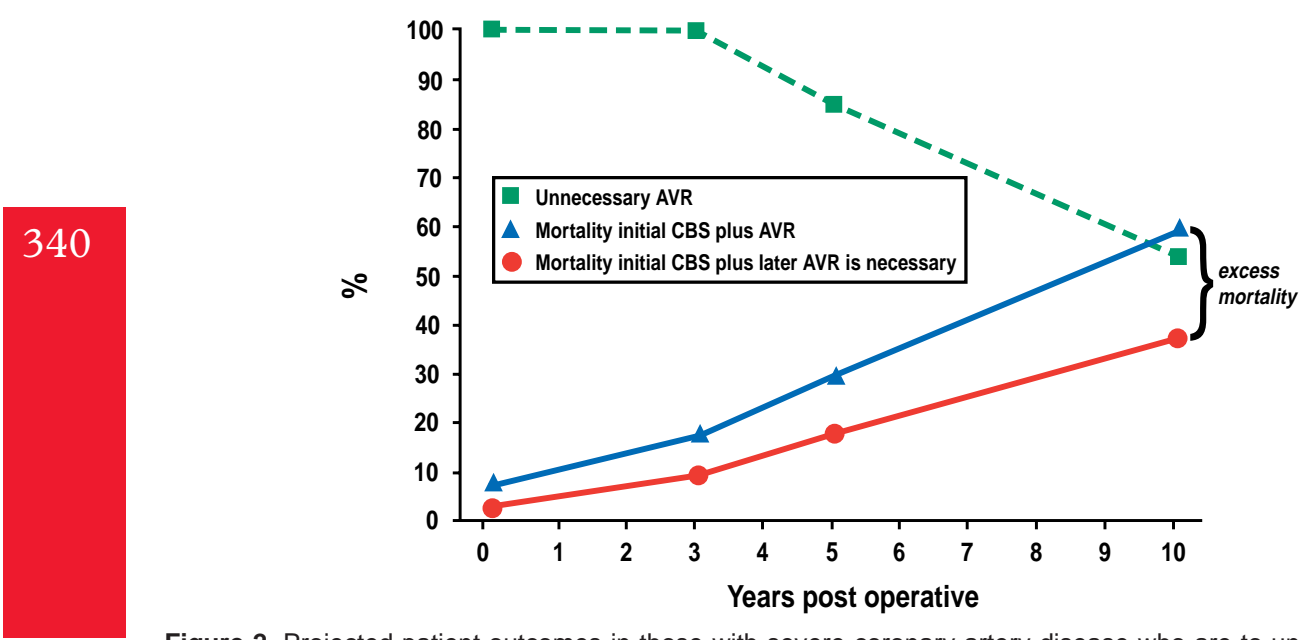

Figure 2. Projected patient outcomes in those with severe coronary artery disease who are to undergo coronary bypass surgery and also have moderate aortic stenosis. AVR, aortic valve replacement; CBS, coronary bypass surgery.

patients. ${ }^{24} 25$ Thus, even if one assumes that $65 \%$ of the survivors who initially did not have AVR will develop severe aortic stenosis (an overestimate) and will need late AVR, and that the operative mortality of late AVR in these patients may be up to $15 \%$ (probably too high), the total number of deaths from late AVR will be quite small.

If initially, 100 patients had CABG+AVR, then at the end of 30 days, three years, and five years, the expected number of unnecessary AVRs would be 100,100, and 85, and the number of excess deaths would be five, nine, and 13, respectively (table 5). It should be noted that the figures for reoperation, and mortality associated with reoperation, are included in the 10 year estimated outcome data in table 5 and fig 2 .

At 10 years, to reduce six deaths from late AVR by a policy of AVR for moderate aortic stenosis at time of initial CABG in 100 patients (table 5), the projected cumulative incidence of unnecessary AVR would be 54 and that of excess deaths would be 24 when compared to a policy of initial isolated CABG and later AVR if necessary (fig 2).

In view of the uncertainty of the rate of progression of calcific aortic stenosis in older patients, at this time CABG for severe coronary artery disease plus AVR may be reasonable for moderate aortic stenosis with an AVA $\leqslant 1.2 \mathrm{~cm}^{2}$ and an AVA index $\leqslant 0.8 \mathrm{~cm}^{2} / \mathrm{m}^{2}$ in patients $\geqslant 60-65$ years of age, provided the patients are not at high risk for thromboembo-

Table 6 Results after 10 years of a policy of initial $C A B G+A V R$ for mild and moderate aortic stenosis

\begin{tabular}{lll}
\hline & $\begin{array}{l}\text { Severe CAD } \\
\text { and mild AS: } \\
\text { 100 patients }\end{array}$ & $\begin{array}{l}\text { Severe CAD } \\
\text { and moderate } \\
\text { AS: 100 patients }\end{array}$ \\
\hline - To eliminate: & & \\
- late AVR & 9 & $46^{\star}$ \\
- deaths from late AVR & 2 & 7 \\
- Results in & & \\
- unnecessary AVR & 91 & 54 \\
- excess deaths & 29 & 24 \\
\hline
\end{tabular}

^An overestimate- see text.

AS, aortic stenosis; CAD, coronary artery disease. lism, ${ }^{11}$ and thus can receive a biological valve (bioprosthesis). ${ }^{11} 22$

In patients who initially had only CABG, at the time of subsequent AVR there is a risk of damage to internal mammary and vein grafts. Although this risk is small with appropriate care, and with skilled and experienced surgeons, it must be recognised this risk applies to reoperation in both subgroups (CABG and CABG+AVR).

1. Collins JJ, Aranki SF. Management of mild aortic stenosis during coronary artery bypass graft surgery. $J$ Cardiovasc Surg 1994;9(suppl):145-7.

2. Odell JA, Mullany CJ, Schaff HV, et al. Aortic valve replacement after previous coronary artery bypass grafting Ann Thorac Surg 1996;62:1424-30.

3. Fighali SF, Avendaño A, Elayda MA, et al. Early and late mortality of patients undergoing aortic valve replacement after previous coronary artery bypass graft surgery. Circulation 1995;92(suppl II):II-163-68.

4. Rahimtoola SH. "Prophylactic" valve replacement for mild aortic valve disease at time of surgery for other cardiovascular disease? No. J Am Coll Cardiol

1999;33:2009-15.

- A review detailing problems of the relevant studies, and assessment of severity and progression of aortic stenosis. Also presents suggested management of such patients.

5. Hoff SJ, Merrill WH, Stewart JR, et al. Safety of remote aortic valve replacement after prior coronary artery bypass grafting. Ann Thorac Surg 1996;61:1689-92.

6. Sundt TM, III, Murphy SF, Barzilai B, et al. Previous coronary artery bypass grafting is not a risk factor for aortic valve replacement. Ann Thorac Surg 1997;64:651-8.

7. Spodick DH. Revascularization of the heart numerators in search of denominators. Am Heart $J$ 1971;81:149-57.

- An early article describing the problem of assessing

patient outcome after treatment when the outcome of the total number of patients with that disorder is not known.

8. Turina J, Hess $O$, Sepulcri F, et al. Spontaneous course of aortic valve disease. Eur Heart J 1987;8:471-83.

- A study that details the natural history of all grades of aortic valve disease.

9. Horstkotte D, Loogen F. The natural history of aortic valve stenosis. Eur Heart $J$ 1988:9(suppl E):57-64.

- A further study detailing the natural history of aortic stenosis.

10. Rahimtoola SH. Perspective on valvular heart disease: an update. J Am Coll Cardiol 1989;14:1-23.

- A review of several aspects of valvar heart disease

including that of the natural history of aortic stenosis and grading its severity (155 cited references).

11. Bonow RO, Carabello B, de Leon AC Jr, et al. ACC/AHA guidelines for the management of patients with valvular heart disease. J Am Coll Cardiol 1998;32:1486-8. - An exhaustive review of valvar heart disease with guidelines on diagnosis and management (102 pages, 737 cited references). 
12. Rahimtoola SH. Severe aortic stenosis with low systolic gradient: the good and bad news. Circulation

$00 ; 101: 1892-4$

A review of severe aortic stenosis with low ejection fraction and low aortic valve gradient, emphasising the importance of early diagnosis and management.

13. Feigenbaum $\mathbf{H}$. Echocardiography, 5th ed. Philadelphia: Lea \& Febiger, 1993:195-6.

14. Griffith MJ, Carey C, Coltart DJ, et al. Inaccuracies of using aortic valve gradients alone to grade severity of aortic stenosis. Br Heart J 1989;62:372-8.

- A large study documenting the need to obtain aortic valve areas to assess severity of aortic stenosis.

15. Connolly HM, Oh JK, Schaff HV, et al. Severe aortic stenosis with low transvalvar gradient and severe left ventricular dysfunction: result of aortic valve replacement in 52 patients. Circulation 2000;101:1940-6.

16. Rahimtoola SH, Fessler CL, Grunkemeier GL, et al. Survival 15 to 20 years after coronary bypass surgery for angina. J Am Coll Cardiol 1993;21:151-7.

17. Davis KB, Chaitman B, Ryan T, et al. Comparison of 15-year survival for men and women after initial medical or surgical treatment for coronary artery disease: a CASS registry study. J Am Coll Cardiol 1995;25:1000-9.

18. Alexander KP, Anstrom KJ, Muhlbaier LH, et al. Outcomes of cardiac surgery in patients age $\geqslant 80$ years: results from the national cardiovascular network. J Am Coll Cardiol 2000;35:731-8.
- A study of over 67000 patients describing the operative mortality of isolated aortic and mitral valve replacement and when combined with associated coronary bypass surgery.

19. Cohn LH, Collins Jr JJ, Rizzo RJ, et al. Twenty-yea follow-up of the Hancock modified orifice porcine aortic valve. Ann Thorac Surg 1998;66:S30-4.

20. Peterseim DS, Cen Y-Y, Cheruvu S, et al. Long-term outcome after biologic versus mechanical aortic valve replacement in 841 patients. J Thorac Cardiovasc Surg 1999;117:890-7.

21. Kirklin JW, Barrat-Boyles BG. Aortic valve disease. In Cardiac surgery, 2nd ed. New York: Churchill Livingstone, 992:491-57

22. Hammermeister KE, Sethi GK, Henderson WG, et al. Outcomes 15 years after valve replacement with a mechanical versus a bioprosthetic valve: final report of the A randomized trial. J Am Coll Cardiol 2000;36:1152-8.

23. Kennedy KD, Nishimura RA, Holmes DR, et al. Natural history of moderate aortic stenosis. J Am Coll Cardiol 1991;17:313-19.

24. Wagner S, Selzer A. Patterns of progression of aortic stenosis: a longitudinal hemodynamic study. Circulation 1982;65:709-12.

25. Nestico PF, DePace NL, Kimbris D, et al. Progression of isolated aortic stenosis: analysis of 29 patients having more than 1 cardiac catheterization. Am J Cardio 1983:52:1054-8. 